\title{
Dialectics of social development and consciousness in the context of systemic approach
}

\author{
Guli Makhmudova ${ }^{1, *}$ \\ ${ }^{1}$ National University of Uzbekistan named after Mirzo Ulugbek, Uzbekistan, Tashkent
}

\begin{abstract}
The present article deals with the dialectics of social development and social consciousness. The author also considers the problems of public consciousness in the context of a systematic approach, in particular, and generality of the process of social development. The author considers the history of the development of human society, the global goals of education and upbringing, as well as their dynamics in accordance with philosophical, methodological concepts, paradigms of education and other reasons. Philosophical categories change in accordance with the expansion of the object of study. For example, modern scientific knowledge studies complex systemic objects, and some classical philosophical ideas cannot provide adequate knowledge. Therefore, such philosophical categories as determinism, randomness, uncertainty, chaos, society, state, human being, good and evil, beautiful and ugly, and others acquire somewhat different functions in the study of modern complex systems compared to their interpretation as classical categories of philosophy.
\end{abstract}

\section{Introduction}

The most difficult problem of the first half of the 21 st century, the difficulty of solving which is increasing every decade, is the regulation of society, the regulation of humanity. The objective basis for its strengthening is, on the one hand, an unprecedented acceleration of population growth on earth; in this regard, we recall that within just one XX century, the number of people on earth increased from 2 billion at its beginning and to 5.5 billion at its end, that is, about 3 times. And this despite the two world wars that first took place in the history of mankind and claimed tens of millions of men of childproducing age. There is a further increase of population growth on Earth, which is inevitable with the ongoing improvement of medical services to the population. Secondly, the problem is not limited to the numerical growth of mankind. A subjective factor comes in the form of an increase in the education of the population, its ability to analyze what is happening in the world, the desire of each person to take a more active and more conscious participation in public life. The third factor that complicates the regulative measures regarding humanity and society many times over is every-year boost of scientific and technological progress, which

\footnotetext{
* Corresponding author: ms.makhmudova@inbox.ru
} 
is practically unthinkable in the past, which is practically equivalent to a multiple increase in the population on the Earth.

We can note similar works on our topic, but still do not reflect the full picture of the system approach to the development of consciousness in society: I. Barna, M. Andron, S. Dobrota. et al. [1], Usmanov B. F. [2], Prokhorov M. M.[3], Moiseev S. P. [4], Yazdonov, S. Z., \& Shavkiev, S. O.[5], I. Arzimatova, [6], M. Asefi, S. salhi et al. [7], E. Muraille [8], K. Vaesen, J. Katzav [9], Agatstsi E. [10].

The problem of searching, finding and creating a world-wide and comprehensive system for human regulation requires its maximum mental and organizational mobilization, which should be introduced not by general declarations and appeals, but by deeply thought-out preparatory work at the lower and upper levels. At the same time, it means laying the solid foundations of a new humanity, which will forever leave behind themselves the inevitable past centuries of adolescence and youth, of course, with full regard for all the positive that was achieved and conquered in previous epochs of historical development.

Here, an important role is played by consciousness, social consciousness and, in general, the change of stereotypes into the worldview of a modern person. In this regard, global philosophical thought is increasingly asserted in the fact that "a democratic society does not succeed until general education gives people a philosophical worldview"[Whitehead A. N., 11]. The philosophical concept of modern postclassical science and social change should take into account the phenomenon of nonlinearity, the manifestation of its laws in our lives. Also, such concepts as the "butterfly effect", a small effect causes a cardinal change, etc., were not considered in classical philosophical concepts. The philosophical concept along with the classical vision of the world should be based on such achievements of modern science as the theory of self-organization, the theory of dissipative structures, synergetics, autopoiesis, which is a new modern vision of increasingly complex interconnected systems. It must correspond to the spirit and challenges, risks of the modern world and modern requirements of society.

Social development is a historical phenomenon, the result of which determines the level of social development, the essence of the individual and personality. In this process, the historical experience of the people, social groups and strata is important. Changes occurring in the human and social strata lead to a change in the content of public consciousness. The main issue today is changing the way people think. The reason for this is the complexity of the world. Complex systems are not enough to realize and understand in traditional way of thinking. Consequently, a need for searching a different way of thinking arises. That is systemic thinking. Systemic thinking is an approach that helps to understand the patterns and meaning of the observed phenomena. Systemic thinking is the ability to see not only parts of the whole, but also the connections between them. According to M. Agazzi, 'as being engaged in philosophy essentially means to think about it, understand it with the help of thoughts, then it obviously follows that to the extent that the complex nature of science in the modern world has become apparent the philosophy of science also must direct its reflection on the nature and consequences of this complexity, notes S. I. Platonova [12]

\section{Methods and methodology}

The changes taking place in Uzbekistan, like in a drop of water, reflect all layers of democratic trends around the world. In the Republic of Uzbekistan, where certain conservative elements of national identity are still strong, the struggle for a new life is becoming multi-layered.

Often, partly very categorically, in public opinion they speak about the unproductive, backwardness and methodologically outdated significance of modern Uzbek philosophy. Although, as M. Agazzi notes, 'The abundance of results obtained within the 
framework of individual methods of thinking (which we could roughly and traditionally designate as phenomenological, semiotic, axiomatic, deductive, reductive, hermeneutic, transcendental, historical) of genuine philosophical knowledge, and pointing to it, we can answer the frequently repeated complaints that we are living in a period of philosophy decline, because we do not have "great thinkers" capable of creating "great the systems" of thought' [S. I. Platonova, 12].

We first became seriously and realistically aware of the essence of a human being as the totality of all social relations. Proceeding from this proven idea, we set a goal - to change the world, rearrange the thinking, consciousness and psychology of people. In the "Strategy for the Further Development of the Republic of Uzbekistan" such need is emphasized: 'stimulating scientific-research and innovative activity, creating effective mechanisms for introducing scientific and innovative achievements into practice, creating specialized scientific laboratories at higher educational institutions and research institutes, centers of high technologies, technology parks' [13], which contributes to the further and accelerated pace of self-organization of society as a whole and in particular of individual consciousness.

In this regard, the common causes of inhibition on the path to the full realization of individual self-affirmation can be noted by three interrelated common causes: historical, ideological and psychological. The question arises, time requires geniuses, smart, etc. One cannot disagree with the opinion of E. Ilyenkov, who states, "The "Mind" ("wisdom") is not "knowledge" in itself, not a totality of information laid down by education in memory, not information and not a totality of rules for combining words with words, terms with terms. This is the ability to properly manage the knowledge, the ability to correlate this knowledge with facts and events of real life, objective reality, and most importantly, to independently acquire and replenish this knowledge - this is how long ago any smart philosophy defined the mind'. [Faibyshenko V., 14] It confirms the statesment that the formation of people's feelings of freedom, democracy, social and creative activity, which are being introduced into the minds of people, gives a wide deployment of ideas and tasks in socio-historical changes.

In Uzbekistan, in all spheres of science and education, a new methodology of scientific knowledge is being formed, requiring the integration of various branches of knowledge and the modernization of the educational process. The modern world and transformations in the social and spiritual life of the republic, modern problems of the development of science, the formation of national youth self-awareness, and the processes of renewal during the independence period are the main spiritual and historical sources of development of modern Uzbekistan. All these processes contribute to the global integration of not only science and education, but also the accelerated integration of our country into the world community.

There are some laws of rhythm, laws of periodic change of states: rise - decline stagnation - rise, etc. Only obeying these "rhythms of life", vibration modes, complex systems can maintain their integrity and dynamically develop. Development always assumes: what was, what is and what will be. Everything that is known motivates people to the real action, but in the present, not all phenomena are "felt", not all ways to see and express the obsolete, disturbing, even disguised "progressive" phenomenon [Kamarudin Z., 15].

\section{Results and discussion}

According to the statement of E. Ilyenkov, 'The personality is all the more significant, the more fully and wider it is represented in it - in its deeds, in its words, in actions - collectively universal, and not at all its purely individual originality. The uniqueness of a genuine person lies precisely in the fact that in its own way it reveals something new for everyone, better than others and more fully than others expressing the "essence" of all other people, by its own activities pushing the limits of available opportunities, opening for everyone what they 
still don't know, they do not know how, do not understand. Its uniqueness is not in the ability to stick out one's individual peculiarity, "dissimilarity" to others, or "bad personality" but only in the fact that, for the first time creating (discovering) a new universal, it acts as an individually expressed universal'[Faibyshenko V., 16].

Therefore, the formation of the essence of social consciousness occurs through the formation and development of personality under the influence of a certain social environment and events, the manifestation of individual characteristics in this process. Of course, the similar way of thinking and mode of speech among all representatives of society or any particular social group are impossible, but the difficulty lies in achieving of positive effectiveness, ensuring stability, in directing their mutual connection to a common goal and interests.

In order to exclude the idea of the "phantom" of social consciousness that may arise, let us Supplement our reflections with the statement of modern scientists that this phenomenon does not exist in addition to the consciousness of individuals who form this community. To this conclusion, we can add a rather long-standing consideration of Durkheim (1899) about the fundamental difference between group thinking and action from the reactions of its participants, if they are separated.

The content of public consciousness is determined by its variability with respect to the constituent parts of the structure in accordance with the worldview, experience, style or way of thinking, the changeable and contradictory processes of reality, because public consciousness, as a whole, consists of complex and interconnected elements. According to Kamarudin Z. statement, 'There is a complex process of the relationship between a person and era, between the individual and society, between people and nature. The socio-historical practice of mankind has so accelerated its movement that at every step we feel how much the content of time has condensed. The pace of life and the breadth of social transformations have expanded the traditional idea of the stillness of time. The stream of social, political and aesthetic information that a modern person consumes is so wider and denser today that it cannot but affect the spiritual essence and creative opportunities of the individual'. [Kamarudin Z., 17]

Consequently, as a result of historical development, alongside with clear and concrete thinking, humans form abstract and generalized way of thinking. However, there is no "great wall of China" between these forms of thinking; on the contrary, they enrich each other, change places, one generates and complements the other. Modern intensive life activity strengthens the need for complex thinking.

Here we can draw an analogy with the conclusion of academician Lapin N. I. (1991) in relation to philosophical knowledge, which, according to the scientist, carries an eternal message, like a baton passing from generation to generation of people and thus becoming an eternal value of our civilization. This can also be called the dualism of philosophy: it belongs to the entire process of human development and at the same time is historically concrete; it is formed by a real society of a specific time period and is part of the world historical process. At the key moments of history, philosophy tries to cover all the contours of dramatic breaks in culture, thinking, and social formations and becomes in a situation of contradictory discord with the world and with itself, which is necessary during the painful birth of new thinking.

In this regard, in the activity of public consciousness, the process of separating thought from representation is difficult, since thought is impossible without representation, and representation cannot exist without thought. Despite this, specific aspects, signs and facets of the individual form of thinking and abstract, theoretical concepts that make up the thinking process begin to appear. For example, "the study of the transformation of modern science has become relevant", since it demonstrates both epistemological and social significance. For example, mentioning social factors, the scientist notes that modern society is characterized by the rise of the status of science and technology, and knowledge itself is now the main 
value. However, she goes on to say that actions in a new complex world also require new thinking in terms of methodology, which in turn creates the need to update the methodology of the cognitive process. The historically established and differing from each other specific features of the artistic, scientific, aesthetic, religious, moral, political, legal forms of public consciousness can be pointed here. Among these forms of social consciousness, artistic, moral, religious and aesthetic forms are closer to each other and contain similar features.

Despite this, each of these forms, the main driving force of which is distinct, clear and concrete-sensual representations, has specific features within the framework of their action and functioning. Perception, awareness of the truth leads to the appearance of a generally accepted representation of certain ideas in various fields of science as an integrated system. Does consciousness and thinking change in this case? If a change is a process of manifestation of diversity, then, naturally, the question arises of what phenomena and why it is associated with necessity. Indeed, the changes that are taking place lead to the change in social conditions, world-wide innovations in modern world science, new ideas and the traditional potential that underlies thinking. The wave of philosophical understanding of changes in people's minds creates a new world of thinking about philosophical ideas and philosophy of life. Another important aspect of this issue is the manifestation of the development of the scientific potential and forces characteristic of each person, the intensification of the possibility of their manifestation with the creation of a moderate social environment.

Spirkin A. G. confirms the previously mentioned conclusion about the duality of consciousness, which can belong to the subject and at the same time exist in the General space of thinking. At the same time, the scientist formulates, the consciousness of the community is not a simple addition of the consciousnesses of its members, but rather a separate spiritual system, which can be said to have its own Autonomous life. On the contrary, individuals themselves move away from the individual, moving to the positions of society.

In this sense, the structure of modern social consciousness as a complex system is associated with material and spiritual activities. Public consciousness, on the one hand, reflects these types of activities, since without activity the growth and development of human consciousness is impossible. 'According to the new concept of a human being, an individual is considered inextricably linked with certain time and space. The social way of life gives rise to individual personality traits, while the person changes his lifestyle in accordance with the socio-historical process. The essence of the personality is determined primarily by its social, political and vital interests'. [Kamarudin Z., 17]

Material and spiritual activity, in turn, completely covers all the feelings and needs of a person (religious, artistic, aesthetic, scientific, technical, mental, physical and others). This activity is the ascent of a person from necessity to voluntary skills, understanding the essence and direction of his activity. This ascent at the same time shows the level of consciousness. Awakening of consciousness determines its actions, and action accelerates the formation of consciousness.

The formation of human goals and hopes indicates that their lifestyle has changed. And this is true for all subsequent historical periods of human development. The hopes and goals of people have become a spiritual factor that changes their lifestyle. The problem of searching, finding and creating a world-wide and comprehensive system for managing mankind requires its maximum mental and organizational mobilization, which should be introduced not by general declarations and appeals, but by deeply thought-out preparatory work at the lower and upper levels.

Knowledge in thinking reflects not only the interconnectedness of objects and phenomena, but also their quality and essence. With the help of thinking, a person, based on his specific goals and conditions, begins to distinguish between the basic and necessary signs 
of objects and phenomena. Then the process of generalization takes place, starting from singular and special, random and undeserving qualities in the direction of general and necessary aspects. Therefore, thinking consists of cognition, generalizing objects and phenomena of reality.

Thinking is a reflection of human actions in reality, as well as analysis and synthesis of the results of these actions. Every action involves a relationship, and a relationship is an activity, and activity, in turn, determines the style, image, shape and direction of thinking.

Thinking is a process of reasoning, which is determined by concepts. The stability and mobility of concepts, their interconnection, addition, change of each other demonstrates the incomparability and continuity of human activity. Continuous action and the process of thinking at the same time is a "way of life" of stability and variability of concepts. This process determines the essence of philosophical thinking and interest in philosophy shows the level of development of strategy in human thinking. This corresponds to an intense and complex reality.

As a result of this, the stereotypes existing in thinking change. However, a change in consciousness is not an instantaneous process. Under this we should understand the scale of the new generation, "hardened" in reforms, changed and transformed social processes. Despite the fact that a change in the stereotypes that have long existed in the public consciousness has long changed the attitude not only towards life, society, the system, but also towards ourselves, national self-consciousness, it is difficult to answer the question of whether this construction corresponds to time or not.

Various socio-political factors of our time on a regional scale cannot but influence the society. With the knowledge of reality, a person enters the process of free thinking. Consequently, there are common features of philosophical, religious, artistic and aesthetic thinking in their influence on the sensory perception, ideas, spiritual and psychological world of a person and their formation, and having a specific, substantial difference and a difference in direction, they personify a symbol of power and power, directing to unanimity, solidarity in the process of social development and overcoming its hardships. Due to the proximity of artistic and aesthetic consciousness, which complement each other, they remain the main factors that express the creative activity of a person. The true appearance of people who have changed in conditions of independence, who possess and display self-awareness, and are also newly formed and developed, is determined by their creative and practical activities, modernity, in which their way of thinking is manifested.

Analysis, personal conclusion, judgment and a critical look are the qualities that are the driving force of modern consciousness and the thinking system. In this sense, we can say that any change, renewal, including democratic reforms, the transition from a planned economy to a market economy, modernization is not based on old, but new, adequate to this period ideas. Nowadays, the status of knowledge is rising, which is turning into the main source of development of society. For the flight of consciousness and thinking, inspiration, sensations, thought, a stable social environment and philosophy are necessary. Such a psychological chain is realized with an organic relationship, the harmony of vertical and horizontal relations in social development. What attracts one person to another is not a word, but a particle of spiritual unity that exists in both. If a person sees one hundred thousand miracles and prophecies, but he does not have a suitable part for the guardian and the prophet, they will not unite, and this will be useless. Therefore, for the correct and concrete presentation of the essence of modern consciousness, the results of deep speculation, thinking, analysis and discussion, which can recognize complex socio-political phenomena, are necessary, psychological and spiritual unanimity is necessary.

For the creators of a "new world without exploitation and inequality", philosophy was a servant, a means and an instrument of totalitarian socialism, and not the very foundation of a self-arising cardinal line of human development. The philosophy of the period of totalitarian 
socialism was the means at the disposal of the leadership, used for the sake of their needs. Totalitarian socialism, in essence, is fighting for the creation of a homogeneous society as an ideal means of achieving goals. However, it has long been known that the achievement of such homogeneity is impossible, as well as the achievement of absolute truth. Humanity was, is and will be heterogeneous. The degree of heterogeneity depends on the state and level of cognition, knowledge and education. Cognition, however, is "constructed" from wordsconcepts. It exists as a process insofar as the world of words exists. Each word has the right to exist insofar as no other word coincides in meaning. It is unique except for its analogs of varying degrees of proximity. The aim is to get as close as possible to the goal, to the unity in the struggle of opinions. Homogeneity is a process that leads to unity. Homogeneity is achievable. Homogeneity is attainable relatively within the limits of the efforts and skill of those who are united.

By the end of the XX century and by the early XXI century, the mankind, having relatively finished with the forcibly imposed teachings and ideologies, has entered the boundless scope of manifestation and practical application of their knowledge and skills. There is an unprecedented acceleration in the rate of human development, conquest of space and time, assimilation and implementation of the latest achievements of science and technology in everyday politics and practice.

Modern society is an open society where everything is decided on the basis of the maximal mobilization of forces, intelligence, energy, and the ability to focus on purposeful activity. The modern generation was not born to continue to be consumers of the natural resources. It must expand and deepen the transformation of nature more and more in order to subordinate it to the will of reason more completely. Humanity passes from an opportunist to a hostile nature, to its conformity, to its cognitive and creative goals. This will open up new horizons for humanity, leading it to the distance of progress, when it ceases to be a slave of a private property.

The question arises: what kind of philosophy is needed under the conditions of globalization; what subject it should be introduced in education. If we take into account the basic credo of philosophy, the worldview, how should we bring closer and overcome that facet in education in relation to this ancient science?

\section{Conclusion}

Through the development and essence of its content, forms, structure and tasks, public consciousness determines the spirit of the times and is important in implementing the strategy of social development.

In the process of social development, specific systems are also constructed in each form of social consciousness. Along with the individual, personal characteristics and qualities of a person, the social environment, the national tradition and the features of the development of society also take part in them immanently. If the psychophysiological structure of a person indicates that he is a conscious being, then the content and scale of social consciousness shows the continuity of social relations, national traditions and spiritual values. When it comes to the extremely difficult forming and developing social consciousness, it is impossible to unequivocally answer the question which of its physical and spiritual potentials are primary and which are secondary. The study of complex consciousness from modern positions and requirements within the framework of considering a person as a creature with a holistic consciousness will always remain relevant, complex and significant.

In Uzbekistan, in all spheres of science and education, a new methodology of scientific knowledge is being formed, requiring the integration of various branches of knowledge and the modernization of the educational process. The modern world and transformations in the social and spiritual life of the republic, modern problems of the development of science, the 
formation of national youth self-awareness, and the processes of renewal during the independence period are the main spiritual and historical sources of development of modern Uzbekistan. All these processes contribute to the global integration of not only science and education, but also the accelerated entry of our country into the world community.

There are some laws of rhythm, laws of periodic change of states: rise - decline stagnation - rise, etc. Only obeying these "rhythms of life", vibrational modes, complex systems can maintain their integrity and dynamically develop. [Knyazeva, H., Kurkina, E., 18] Development always assumes: what was, what is and what will be. Everything that is known raises people to the real action, but in the present, not all phenomena are "felt", not all ways to see and express the obsolete, disturbing, even disguised "progressive" phenomenon. It is this society, in which the weight from great to low, live in a state of constant mobilization in the search and finding new, more profitable and more promising areas of enrichment and there is an ideal stream around which the engine of progress is formed and works. Such an understanding of the organization of life, in principle, is quite satisfactory for everyone when supplemented by a higher authority that prevents deviations from its general principles.

\section{References}

1. I. Barna, M. Androne, C. Dobrotă, Procedia - Social and Behavioral Sciences 47, 17701774 (2012) doi: 10.1016/j.sbspro.2012.06.898

2. B.F. Usmanov, Sociology and life 2, 87-98 (2015) DOI: 10.17805/zpu. 2015. 2. 9

3. M. Prokhorov, Philosophy and culture 3, 320-336 (2016) DOI: 10.7256/24540757.2016.3.16849

4. S.P. Moiseev, Monitoring of public opinion: economic and social changes, 233-244 (2017) DOI: 10.14515/monitoring.2017.2.12

5. Z.S. Yazdonov, O.S. Shavqiyev, ISJ Theoretical \& Applied Science 10(66), 515-518 (2018) https://dx.doi.org/10.15863/TAS.2018.10.66.60

6. I. Arzimatova, Scientific Bulletin of Namangan State University 1(1), 21 https://uzjournals.edu.uz/namdu/vol1/iss1/21

7. M. Asefi, S.S. Khasraghi, A.P. Roders, Frontiers of Architectural Research 8(1), 66-79 (2019) https://doi.org/10.1016/j.foar.2018.12.003

8. E. Muraille, $\quad$ Endeavour 100709 https://doi.org/10.1016/j.endeavour.2020.100709

9. K. Vaesen, J. Katzav, Studies in History and Philosophy of Science Part A 78, 73-82 (2019) https://doi.org/10.1016/j.shpsa.2019.01.001

10. E. Agatstsi Philosophy questions 9, 60-65 https://www.elibrary.ru/item.asp?id=22400141

11. A.N. Whitehead, Adventures of ideas (IFRAN, Moscow, 2009) https:/iphras.ru/uplfile/root/biblio/2009/Whitehead.pdf

12. S.I. Platonova, Sociology of science: evolution of the main programs https://doi.org/10.24158/spp.2018.4.1

13. Ukaz Prezidenta Respubliki Uzbekistan 'O Strategii dejstvij po dal'nejshemu razvitiyu Respubliki Uzbekistan. Sobranie zakonodatel'stva Respubliki Uzbekistan (2017) http://lex.uz

14. V. Faibyshenko, Logos 27(5), 45-63 (2017) DOI: 10.22394/0869-5377-2017-5-45-62 
15. Z. Kamarudin, Pacific Science Review B: Humanities and Social Sciences 1(3), 109-113 (2015)

16. H. Knyazeva, E. Kurkina, Thinker of interdisciplinary Epoch. Voprosy filosofii (Akademiia nauk SSSR, Institut filosofii, 2009) 